\title{
The amygdalo-nigrostriatal network is critical for an optimal temporal performance
}

\author{
Mouna Es-seddiqi, ${ }^{1,2}$ Nicole El Massioui, ${ }^{1,2}$ Nathalie Samson, ${ }^{1,2}$ Bruce L. Brown, ${ }^{3,4}$ \\ and Valérie Doyère ${ }^{1,2}$ \\ ${ }^{1}$ Université Paris-Saclay, Univ Paris-Sud, CNRS, UMR9197, Institut des Neurosciences Paris-Saclay, F 91405, Orsay, France;
${ }^{2}$ CNRS, Orsay, F-91405 UMR 9197, Orsay, France; ${ }^{3}$ Department of Psychology, Queens College, Flushing, New York 11367, USA;
${ }^{4}$ Graduate Center, City University of New York, New York, New York 10016, USA
}

The amygdalo-nigrostriatal (ANS) network plays an essential role in enhanced attention to significant events. Interval timing requires attention to temporal cues. We assessed rats having a disconnected ANS network, due to contralateral lesions of the medial central nucleus of the amygdala (CEm) and dopaminergic afferents to the lateral striatum, as compared to controls (sham and ipsilateral lesions of CEm and dopaminergic afferents to LS) in a temporal bisection task. ANS disconnection induced poorer temporal precision and increased response latencies to a short duration. The present results reveal a role of the ANS network in temporal processing.

Temporal processing in the second-to-minute range (i.e., interval timing) is critical for adaptive behavior to contingencies. Recent evidence points to a potential involvement of the amygdala in processing temporal information in Pavlovian conditioning tasks (Díaz-Mataix et al. 2014). Whether it is involved in interval timing in general is not clear. In an appetitive peak interval timing task, lesion or inactivation of the whole amygdala did not disrupt the memory of reinforcement time (Olton et al. 1987; Meck and MacDonald 2007). However, the amygdala has been shown to play a role in the processes underlying divided attention when a dual-task triggers the subject to divert its attention from the timing task (Meck and MacDonald 2007). More specifically, the central nucleus of the amygdala (CE) has been shown to be involved when changes in temporal parameters produce attentional challenges in a spatial multiple-choice task (Holland et al. 2000), and in the modulation of cue associability when temporal cues are informative (Wheeler and Holland 2011). Recently, we have reported that selective lesions of the $\mathrm{CE}$ of the amygdala have a deleterious impact on temporal precision when assessed in a temporal bisection task (Faure et al. 2013). The foregoing studies suggest that the amygdala, in particular the $\mathrm{CE}$, may influence the processes underlying attention to temporal cues.

The CE is connected to the dorsal striatum, a structure critically involved in temporal processing (for review, see Merchant et al. 2013), via a di-synaptic network connecting its medial part (CEm) to the lateral part of substantia nigra pars compacta (SNc) which sends dopaminergic fibers to the lateral part of the striatum (LS). The amygdalo-nigrostriatal (ANS) network is critically involved in the acquisition and expression of conditioned orienting responses to conditioned stimulus cues associated with a food reinforcer (Han et al. 1997; El-Amamy and Holland 2006). It is thus possible that the ANS network may also underlie temporal orienting (i.e., selective attention to time when subjects are required to make temporal judgments), and thus modulate lateral striatal function critical in processing of time. To investigate this possibility, we used a disconnection lesion design, which takes advantage of the absence of cross-hemisphere connections. We assessed whether animals with contralateral lesions of CEm and dopami-

Corresponding author: valerie.doyere@u-psud.fr

Article is online at http://www.learnmem.org/cgi/doi/10.1101/lm.041152.115. nergic afferents to LS, thus having a disconnected ANS network, show deficits in temporal discrimination, as compared to ipsilateral lesions of CEm and dopaminergic afferents to LS for which the ANS network is functional in one hemisphere. A comparison with nonlesioned controls also tested for a specific effect of unilateral dopaminergic and/or CEm lesion, rather than a dysfunctional ANS network. As the ANS network has also been involved in instrumental habit formation (Lingawi and Balleine 2012), we also tested whether the potential effects may be modified with overtraining.

Thirty male Sprague-Dawley rats (Charles River, Lyon, France), housed in pairs, received neurotoxic or sham lesions. Sixteen weeks later, food-deprived animals (85\% of their normal weight) were trained in the temporal task. All experiments were carried out in accordance with the recommendations of the EEC (86/609/EEC) and the French National Committee (87/848) for care and use of laboratory animals.

Rats underwent surgery under pentobarbital $(50 \mathrm{mg} / \mathrm{kg})$ anesthesia and atropine $(0.25 \mathrm{mg} / \mathrm{mL}, 0.1 \mathrm{~mL}$ i.m). Neurotoxins were injected through a glass micropipette (tip diameter: 70-80 $\mathrm{mm})$ at a rate of $0.1 \mu \mathrm{L} / \mathrm{min}$ with ibotenic acid $(0.2 \mathrm{~mL}, 10 \mathrm{mg} /$ $\mu \mathrm{L})$ for CEm lesion (AP: -2.56 , ML: $\pm 3.9, \mathrm{DV}:-7$ relative to bregma; Paxinos and Watson 1986), and 6-OHDA (0.3 mL/site, $5 \mathrm{mg} / \mu \mathrm{L}$ ) for LS DA deafferentation (AP: +0.2 , ML: \pm 3.6 , DV: -5.6 and -4 , and AP: -0.8 , ML: $\pm 3.9, \mathrm{DV}:-5.6$ and -4$)$, either ipsilaterally or contralaterally. Micropipettes were left in place for 3 additional minutes. Sham animals underwent surgery but without injections. After surgery, animals were given an injection of valium (0.1 mL, i.p., $0.2 \%$, Roche, Neuilly-sur-Seine, France) to avoid seizures.

The behavioral protocols, adapted from Callu et al. (2009), were run using Coulbourn apparatus (USA). Two squads of rats were run, separated by $2 \mathrm{wk}$, with equivalent number of rats from each group. After magazine training (30 pellets) and

\footnotetext{
(C) 2016 Es-seddiqi et al. This article is distributed exclusively by Cold Spring Harbor Laboratory Press for the first 12 months after the full-issue publication date (see http://learnmem.cshlp.org/site/misc/terms.xhtml). After 12 months, it is available under a Creative Commons License (AttributionNonCommercial 4.0 International), as described at http://creativecommons. org/licenses/by-nc/4.0/.
} 
continuous reinforcement (50 pellets) with each lever, the animals were trained in a 2 - versus 8 -sec temporal discrimination starting with $3 \mathrm{~d}$ of $100 \%$ forced choice (presentation of only the correct lever [left or right] associated with the corresponding 2 - or 8 -sec tone duration), followed by $2 \mathrm{~d}$ of $50 \%$ free choice, then by daily sessions of $100 \%$ free choice trials (both levers presented) until each animal reached a criterion of $75 \%$ correct responses in three successive sessions (one Sham rat failed to reach the criterion). The lever was retracted immediately following a response, or after $5 \mathrm{sec}$. The lever-duration assignment was counterbalanced within each group, and the short duration assigned ipsilateral to the side of the dopaminergic lesion for half of the animals of Contra and Ipsi groups. Once the criterion was reached (six to seven sessions), rats were trained on a 2.4- versus 6.7-sec discrimination task for two sessions (all rats reached minimum $85 \%$ correct responses). A psychophysical choice procedure (bisection task) was then conducted for four sessions with five intermediate durations $(2.9,3.4,4,4.7$, and $5.6 \mathrm{sec})$ without reinforcement (12 trials each), in addition to the two reinforced training durations ( 2.4 and $6.7 \mathrm{sec}-60$ trials of each). Two Sham and one Ipsi rats showed unstable behavior from one day to another during these tests, and were thus eliminated. The animals were then run on a set of tests (six daily sessions including three bisection tests), yielding data that are not reported here. Supplementary training (i.e., overtraining) in the 2.4- versus 6.7 -sec discrimination task ( $5 \mathrm{~d}$ of two sessions) was then given, followed by four test sessions of the bisection task. Rats were killed with an overdose of pentobarbital $(120 \mathrm{mg} / \mathrm{kg}$, i.p; Sanofi, Libourne, France), perfused, and their brain taken for histological analysis, as described previously (Faure et al. 2005). Two Contra and three Ipsi rats were eliminated because of a lack of dopaminergic denervation (two rats) or a lack of visible lesion in the CE (three rats). The two groups had similar levels of lesions for the three structures, with the lesions centered in the medial part of the $\mathrm{CE}$, and the lateral parts of the SNc and striatum (Fig. 1).

Response location and latency were recorded for each trial. For the analysis of choice performance during the bisection test, responses with latencies greater than $3 \mathrm{sec}(<0.6 \%$ cases for each group and each training phase) were excluded, because long latency responses are poorly controlled by the stimulus duration (Maricq and Church 1983). For the latency analyses, however, all responses were included. Bisection functions relating the proportion of "long" responses [p(long)] to stimulus duration were averaged across sessions for each rat, and analyzed with the pseudologistic model fit using Prism software (GraphPad Software Inc., La Jolla, CA, USA; Höhn et al. 2011). Statistical analyses were performed with contrast analyses of variance (ANOVAs, Rouanet et al. 1990), based on a priori hypothesis. A role of the ANS network would be revealed through a significant difference in performance between Ipsi versus Contra groups. On the other hand, an effect of unilateral dopaminergic and/or CEm lesion would be indicated by similar disruption between Ipsi and Contra groups, compared to Sham animals. An alpha level of 0.05 was the criterion for statistical significance.

The mean proportion of responses on the lever assigned as correct for the

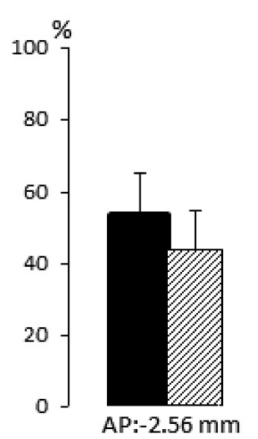

long-duration stimulus [p(long)] as a function of stimulus duration after training is shown for the two lesioned groups against the Sham group in Figure 2A. Each of the two lesioned groups appeared to differ from the Sham group, with a shallower slope and/ or a shift to the right of the bisection function. Statistical analyses of $\mathrm{p}$ (long) confirmed a significant group $\times$ duration interaction $\left(F_{(12,108)}=2.86, P=0.0018\right)$, with no effect of group $\left(F_{(2,18)}=\right.$ $2.17, \mathrm{~ns})$. When testing each lesioned group against the Sham, the analysis revealed significant group $\times$ duration interactions for each comparison (Sham versus Ipsi, $F_{(6,54)}=2.79, P=0.019$; Sham versus Contra, $\left.F_{(6,78)}=3.98, P=0.0016\right)$.

The proportion of variance accounted for by the fit ranged from 0.947 to 0.999 and were similar between groups (mean \pm SEM, Sham $=0.982 \pm 0.009, \quad$ Ipsi $=0.988 \pm 0.004, \quad$ Contra $=$ $0.984 \pm 0.004)$. With regard to the point of subjective equality (PSE, stimulus value corresponding to $\mathrm{p}(\mathrm{long})=0.5$ ), an increase (corresponding to a shift to the right of the bisection function) was observed for both Ipsi and Contra groups (Fig. 2B, left panel). In fact, Ipsi and Contra groups did not differ significantly $(F<1)$, but differed from Sham animals $\left(F_{(1,18)}=4.88, P=0.04\right)$, suggesting that the rightward shift of the bisection functions was due to the unilateral dopaminergic deafferentation to the LS and/or unilateral CEm lesion.

With regard to the temporal sensitivity parameter (gamma, inversely related to the slope), an increase (corresponding to lower temporal sensitivity) was observed for Contra groups, as compared to Sham and Ipsi groups (Fig. 2B, right panel). A Contra versus Ipsi comparison showed a significant difference $\left(F_{(1,14)}=8.23\right.$, $P=0.012)$, while Sham and Ipsi groups did not differ $(F<1)$. These results thus demonstrate an impact of the disconnection of the ANS network on temporal sensitivity. Overtraining produced an overall decrease in gamma from 0.24 to $0.15\left(F_{(1,18)}=\right.$ 24.91, $P<0.001$ ), which however remained significantly higher for Contra than for Ipsi groups $\left(F_{(1,14)}=5.80, P=0.03\right)$. All other effects tended to be reduced with overtraining and were no longer significant.

Response latencies have been shown to correlate with choice complexity and to sometimes differ between short and long
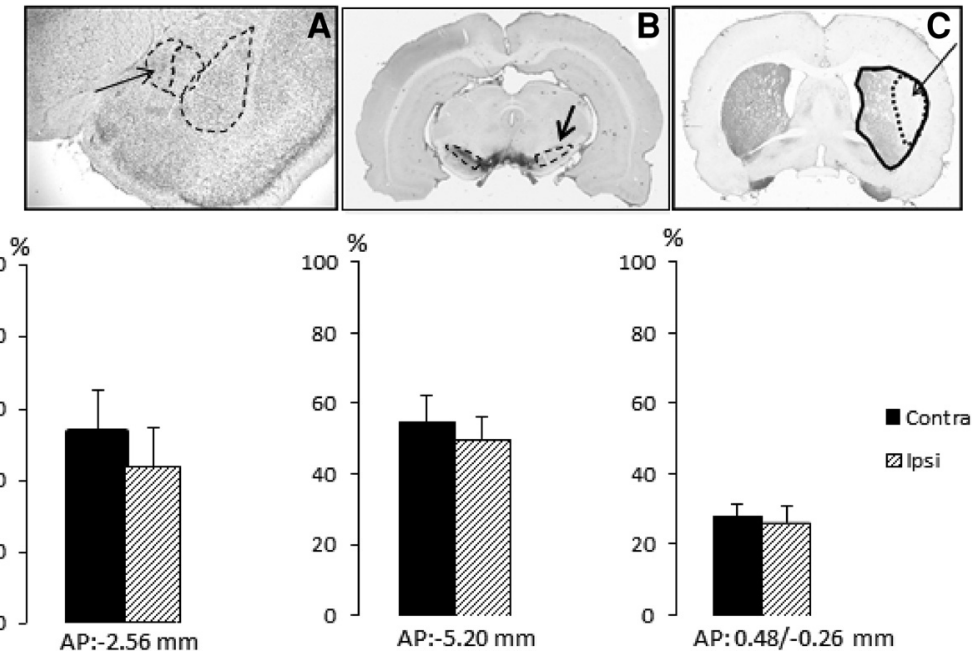

Figure 1. The photographs illustrate Nissl in the CeA $(A)$, and TH immunoreactivity in the $\mathrm{SNc}(B)$ and in the lateral striatum (C), as described in Faure et al. (2005). Lesions were evaluated qualitatively for inclusion/exclusion purposes throughout the A-P extent of the lesion. Quantitative analyses are shown at only the planes shown, as a 50\% lesion at the given anteroposterior level is likely to have involved the entire structure. The histograms represent the average percentage of the lesion area of $C E$, SNc, and DS at anterior-posterior (AP) levels relative to Bregma (Paxinos and Watson 1986) for the Ipsi (striped) and Contra (black) groups. Data are expressed as means + SEM. 

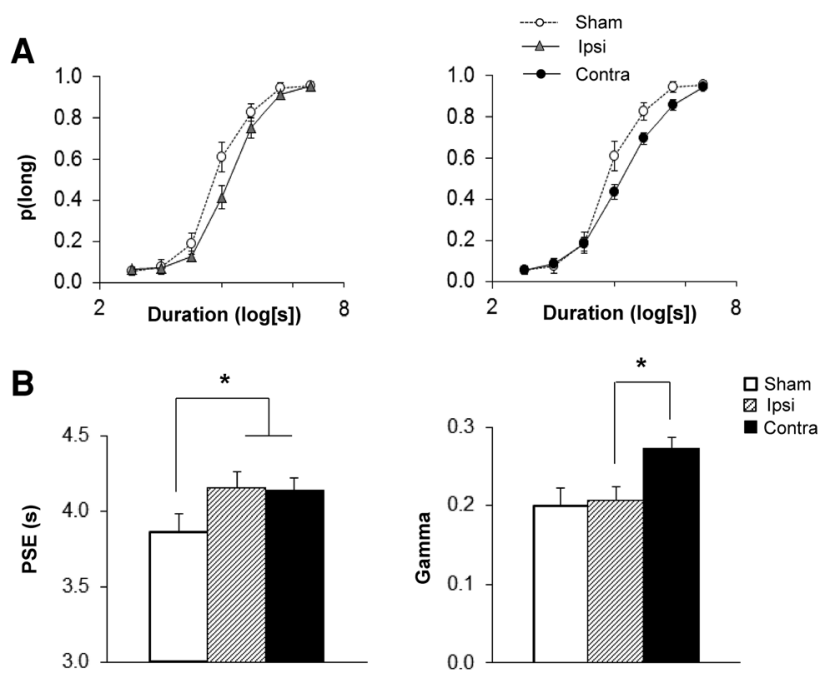

C
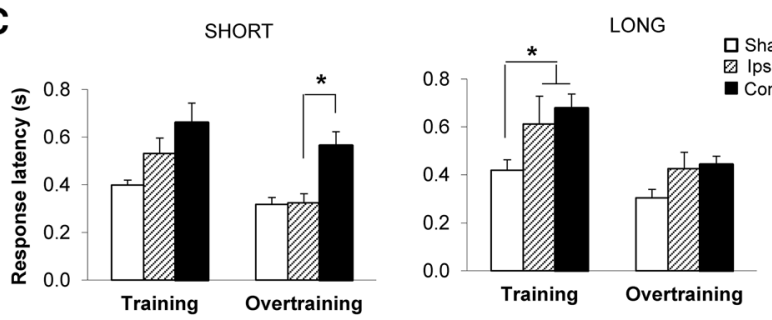

Figure 2. Bisection curves on a log scale for the abscissa $(A)$, temporal parameters extracted from the fitted bisection function (B), PSE (left panel) and gamma (right panel), and response latencies (C) to short (left panel) and long (right panel) anchor durations for Sham (white, $n=5$ ), Ipsi (gray triangle, striped histogram, $n=6$ ), and Contra (filled circle, black histogram, $n=10$ ) lesioned animals. $\left(^{*}\right) P<0.05$.

duration, and to be modified with repeated testing with the intermediate nonreinforced durations (Brown et al. 2011). We thus analyzed response latencies for anchor durations only, during the bisection tests after training and overtraining (see Fig. 2C). Responses of the lesioned animals differed depending on the duration, with a specific impact of network disconnection restricted to the short duration. The Contra versus Ipsi comparison of response latencies following the short duration showed a significant difference after overtraining $\left(F_{(1,14)}=8.33, P=0.01\right)$, but not after training $\left(F_{(1,14)}=1.18, n s\right)$ owing to the intermediate level of Ipsi animals, as Contra animals responded with longer latencies than Sham animals $\left(F_{(1,13)}=4.75, P=0.048\right)$. Following the long anchor duration, however, both lesioned groups showed longer latencies than Sham animals. While Contra and Ipsi animals did not differ significantly after either training, or overtraining $(F s<1)$, the Sham versus [Ipsi and Contra] contrast analysis revealed a significant difference after training $\left(F_{(1,18)}=\right.$ $4.48, P=0.048)$ and a similar trend after overtraining $\left(F_{(1,18)}=\right.$ $4.07, P=0.059)$, suggesting that the increase in latency observed in Contra animals following the long duration may be due to unilateral dopaminergic and/or CEm lesions.

The present study demonstrated that functionally disconnecting the medial part of the central nucleus and the dopaminergic inputs to the lateral striatum impairs supra-second temporal performance by reducing temporal precision (35\% increase in gamma) and increasing response latencies to the short anchor duration ( $\sim 70 \%$ increase), effects that were maintained after overtraining. The results also indicate that animals with unilateral lesions of dopaminergic afferents to the lateral striatum and/or the central amygdala were biased toward short durations (7.5\% increase in PSE for Ipsi and Contra groups), and had increased response latencies to the long anchor duration ( $\sim 60 \%$ increase), effects that tended to diminish with overtraining.

The relationship between dopamine and temporal bisection point (PSE) is usually interpreted in terms of changes in the speed of an internal clock. This cannot account for the results obtained here as the animals were trained while already lesioned, and thus any change in clock speed would not be visible on PSE. A change in motivational state (e.g., related to dopamine levels) may result in a stable bias of the temporal bisection function (for review, see Balci 2014). The fact that response latencies for the long stimulus were increased (possibly reflecting a slight decrease in motivation) for lesioned groups would support such a hypothesis. Interestingly, a change in striatal dopaminergic activity has been shown to modify performance in temporal bisection for long but not for short durations, an effect interpreted as due to decrements in working memory or sustained attention (Ward et al. 2009). Another hypothesis is that the rightward shift of the bisection function reflects weaker stimulus-reinforcer associative strength for the long-duration stimulus as compared to the short-duration stimulus, which would have resulted in a "short" preference. At this stage, we cannot favor one hypothesis over the others, and further experiments will be needed to understand the origin of these effects, as well as whether they are related solely to the unilateral lesion of DA, or to unilateral lesion of CEm or of both CEm and DA (El-Amamy and Holland 2007; Lee et al. 2011).

More important, with regard to our initial goal, the present results suggest a specific role of the ANS network in the modulation of temporal instrumental behavior. With regard to response latencies, the role of the ANS network may be related to the change in conditional probability as time elapses during the timing stimulus. In effect, conditional probability that the stimulus will end and the levers appear increases with time to 1.0 at the long anchor duration, a process which involves cortical areas that project to the dorsal striatum (Nobre et al. 2007). Interestingly though, the impact of the ANS disconnection on response latencies seems to weaken near the bisection point (i.e., around $4 \mathrm{~s}$, data not shown). Therefore, another possibility is that the change with elapsing time in temporal expectation transforms the task from a two-choice to a single-choice comparison, on average at a time after the bisection point (Callu et al. 2009). An asymmetry in the modulation of response latencies for short versus long duration has been previously reported in mice (Akdoğan and Balci 2015), suggesting prospective decision processing during the timing stimulus until a threshold is reached for a "long" judgment, which renders the response to the short duration more dependent on post-stimulus decision dynamics. Thus, the disruption observed here after disconnection of the ANS network, specific to the short duration, confirms the asymmetry in the underlying processes in the temporal bisection procedure, and suggests a role of the ANS network in the comparator/decision processes at play either during or post-stimulus.

The results showing poorer temporal sensitivity (increased gamma) after ANS disconnection are in favor of a role of this network in the processes involved during the timing stimulus. Decreased temporal sensitivity could occur when attention is diverted from the processing of temporal cues, thus resulting in increased variability in temporal perception. As mentioned earlier, the ANS network has been shown to play a role in attentional processing allocated to biologically significant stimuli (Han et al. 1997; Holland et al. 2000). In humans, the processing of temporal expectancy was shown to involve cortical areas that project to the dorsal striatum (for review, see Coull 2010). It is therefore tempting to suggest that the ANS network plays a role in the mechanisms subtending attention to time, a process which 
when disrupted could conceivably also affect response latencies to the shorter stimuli. In effect, our pattern of results suggests that, at least when a two choice task is enforced, attention to elapsing time (i.e., temporal orienting) is required for short durations, and that the ANS network is critically involved in these processes.

In conclusion, the present results unravel a new role of the ANS network in an instrumental task which relies on complex processing and which combines attentional and decision mechanisms. Whether the amygdalo-nigral projections to the LS affect endogenous striatal temporal processing or the simple transformation into action from already processed information in the cortical areas afferent to the striatum is an open question. The results also add further support to the general agreement for a role of the LS and its dopaminergic afferents in interval timing, and extend the role of the amygdala to interval timing.

\section{Acknowledgments}

This work was supported by grants from Agence Nationale de la Recherche (ANR). M. Es-seddiqi was supported by Sopavi. BL Brown's work was supported by PSC-CUNY grant \# 61336-00 39. The authors declare no competing financial interests.

\section{References}

Akdoğan B, Balcı F. 2015. Stimulus probability effects on temporal bisection performance of mice (Mus musculus). Anim Cogn doi: 10.1007/s10071-015-0909-6.

Balci F. 2014. Interval timing, dopamine, and motivation. Timing Time Percep 2: 379-410.

Brown BL, Höhn S, Faure A, von Hörsten S, Le Blanc P, Desvignes N, El Massioui N, Doyère V. 2011. Temporal sensitivity changes with extended training in a bisection task in a transgenic rat model. Front Integr Neurosci 5: 44.

Callu D, El Massioui N, Dutrieux G, Brown B, Doyère V. 2009. Cognitive processing impairments in a supra-second temporal discrimination task in rats with cerebellar lesion. Neurobiol Learn Mem 91: 250-259.

Coull JT. 2010. Neural substrates of temporal attentional orienting. In Attention and time (ed. Nobre AC, Coull JT), pp. 429-442. Oxford University Press, Oxford.

Díaz-Mataix L, Tallot L, Doyère V. 2014. The amygdala: a potential player in timing CS-US intervals. Behav Processes 101: 112-122.

El-Amamy H, Holland PC. 2006. Substantia nigra pars compacta is critical to both the acquisition and expression of learned orienting of rats. Eur J Neurosci 24: 270-276.

El-Amamy H, Holland PC. 2007. Dissociable effects of disconnecting amygdala central nucleus from the ventral tegmental area or substantia nigra on learned orienting and incentive motivation. Eur J Neurosci 25: 1557-1567.
Faure A, Haberland U, Condé F, El Massioui N. 2005. Lesion to the nigrostriatal dopamine system disrupts stimulus-response habit formation. J Neurosci 25(11): 2771-2780.

Faure A, Es-Seddiqi M, Brown BL, Nguyen HP, Riess O, von Hörsten S, Le Blanc P, Desvignes N, Bozon B, El Massioui N, Doyère V. 2013. Modified impact of emotion on temporal discrimination in a transgenic rat model of Huntington disease. Front Behav Neurosci 7: 130.

Han J-S, McMahan RW, Holland PC, Gallagher M. 1997. The role of an amygdalo-nigrostriatal pathway in associative learning. J Neurosci 17: 3913-3919.

Höhn S, Dallérac G, Faure A, Nguyen HHP, Riess O, von Hörsten S, Le Blanc P, Desvignes N, El Massioui N, Brown BL, et al. 2011. Behavioral and in vivo electrophysiological evidence for presymptomatic alteration of prefronto-striatal processing in the transgenic rat model for Huntington's disease. J Neurosci 31: 8986-8997.

Holland PC, Han J-S, Gallagher M. 2000. Lesions of the amygdala central nucleus alter performance on a selective attention task. J Neurosci 20: $6701-6706$.

Lee HJ, Wheeler DS, Holland PC. 2011. Interactions between amygdala central nucleus and the ventral tegmental area in the acquisition of conditioned cue-directed behavior in rats. Eur J Neurosci 33: 1876-1884.

Lingawi NW, Balleine BW. 2012. Amygdala central nucleus interacts with dorsolateral striatum to regulate the acquisition of habits. J Neurosci 32: $1073-1081$.

Maricq AV, Church RM. 1983. The differential effects of haloperidol and methamphetamine on time estimation in the rat. Psychopharmacology 79: $10-15$.

Meck WH, MacDonald CJ. 2007. Amygdala inactivation reverses fear's ability to impair divided attention and make time stand still. Behav Neurosci 121: 707-720.

Merchant H, Harrington D, Meck WH. 2013. Neural basis of the perception and estimation of time. Ann Rev Neurosci 36: 313-336.

Nobre AC, Correa A, Coull JT. 2007. The hazards of time. Curr Opin Neurobiol 17: 465-470.

Olton DS, Meck WH, Church RM. 1987. Separation of hippocampal and amygdaloid involvement in temporal memory dysfunctions. Brain Res 404: $180-188$.

Paxinos G, Watson C. 1986. The rat brain in stereotaxic coordinates. Academic Press, Sydney, Australia.

Rouanet H, Bernard J-M, Le Roux B. 1990. Analyse inductive des données. Dunod, Paris.

Ward RD, Kellendonk C, Simpson EH, Lipatova O, Drew MR, Fairhurst S, Kandel ER, Balsam PD. 2009. Impaired timing precision produced by striatal $\mathrm{D} 2$ receptor overexpression is mediated by cognitive and motivational deficits. Behav Neurosci 123: 720-730.

Wheeler DS, Holland PC. 2011. Effects of reward timing information on cue associability are mediated by amygdala central nucleus. Behav Neurosci 125: 46-53.

Received November 19, 2015; accepted in revised form December 10, 2015. 


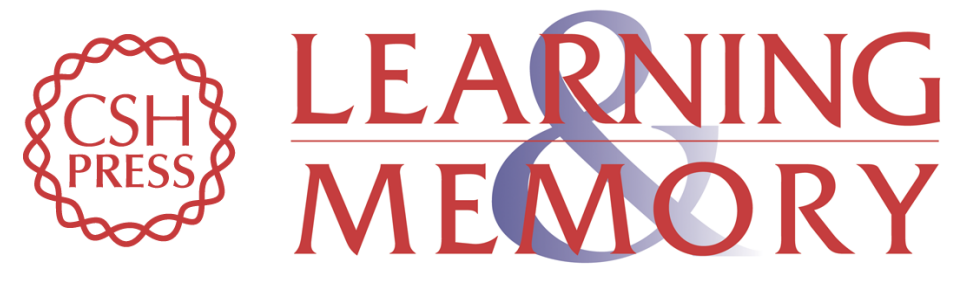

\section{The amygdalo-nigrostriatal network is critical for an optimal temporal performance}

Mouna Es-seddiqi, Nicole El Massioui, Nathalie Samson, et al.

Learn. Mem. 2016, 23:

Access the most recent version at doi:10.1101/Im.041152.115

\begin{aligned} & \hline References $\begin{array}{l}\text { This article cites } 21 \text { articles, } 5 \text { of which can be accessed free at: } \\ \text { http://learnmem.cshlp.org/content/23/3/104.full.html\#ref-list-1 }\end{array} \\ & \begin{aligned} \text { Creative } \\ \text { Commons } \\ \text { License }\end{aligned} \begin{array}{l}\text { This article is distributed exclusively by Cold Spring Harbor Laboratory Press for the } \\ \text { first } 12 \text { months after the full-issue publication date (see } \\ \text { http://learnmem.cshlp.org/site/misc/terms.xhtml). After } 12 \text { months, it is available under } \\ \text { a Creative Commons License (Attribution-NonCommercial } 4.0 \text { International), as } \\ \text { described at http://creativecommons.org/licenses/by-nc/4.0/. }\end{array} \\ & \begin{array}{c}\text { Receive free email alerts when new articles cite this article - sign up in the box at the } \\ \text { top right corner of the article or click here. }\end{array} \\ & \begin{array}{c}\text { Service } \\ \text { terting }\end{array}\end{aligned}$ 